\title{
Dear Readers of and Contributors to Ocean Science Journal
}

\author{
Hae Jin Jeong* \\ Editor-in-Chief
}

School of Earth and Environmental Sciences, Seoul National University, Seoul 151-742, Korea

(c) KSO, KORDI and Springer 2010

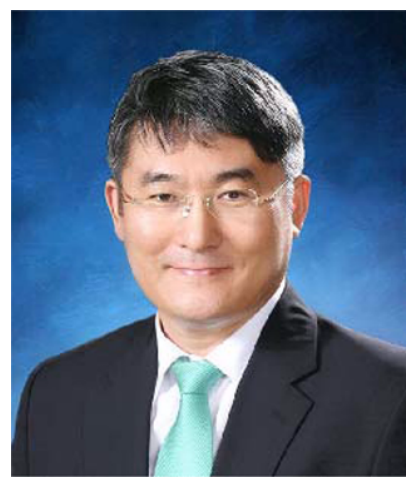

Thank you for your support and encouragement! Published by the Korean Society of Oceanography (KSO) and the Korea Ocean Research \& Development Institute (KORDI), Ocean Science Journal (OSJ), is one of the leading international journals in the field of ocean science in Asia. Our membership, readership and number of manuscripts submitted for publication have rapidly increased. In 2010, articles published in OSJ have begun to be newly indexed by 10 renowned research database systems including the Astrophysics Data System, Google Scholar, and Biological Abstracts in addition to 12 other previously indexed database systems. Due to this increase in exposure, I believe that these articles will become cited more often by scientists in diverse fields.

Moreover, in order to improve submission and review processes as well as increase international distribution, visibility and impact, OSJ has partnered with Springer, one of the largest publishers of scientific journals in the world. Thanks to this partnership, downloads of OSJ manuscripts are rapidly increasing.

The editors, publisher, and editorial staff of OSJ do their best to enhance the quality of this journal continuously, improve submission and review systems in the electronic editorial system (http://www.editorialmanager.com/osjo), and shorten the time from manuscript acceptance to publication. Initially, accepted manuscripts will be electronically published as soon as possible with DOI numbers at the SpringerLink site (http://springerlink.com/content/121339). The publisher allows for open access publication of articles under specific conditions. I believe that this will dramatically increase the availability and eventual impact of papers.

I would greatly appreciate any advice, comments, or suggestions regarding OSJ. Your feedback will very useful in making OSJ one of the leading ocean science journals in the world. I look forward to hearing from you. Thank you for your consideration!

\footnotetext{
*Tel: +82-2-880-6746

E-mail: hjjeong@snu.ac.kr

http://plaza.snu.ac.kr/ hjjeong/
} 